\title{
Política cultural e desenvolvimento: uma análise do Programa Bairro Escola, do município de Nova Iguaçu - Rio de Janeiro'
}

\author{
Cultural policy and development: an analysis of the Program Bairro Escola, in the city of \\ Nova Iguaçu - Rio de Janeiro
}

\author{
Cristiane Simões Netto Costa $^{2}$ \\ Diana Costa de Castro $^{3}$ \\ Vanessa Brulon Soares ${ }^{4}$ \\ Marcel de Souza Silva e Santos ${ }^{5}$
}

\section{Resumo}

O objetivo do trabalho é identificar de que maneira as práticas atuais do Programa Bairro Escola, da Prefeitura de Nova Iguaçu, no Estado do Rio de Janeiro, atendem aos objetivos de desenvolvimento estipulados em sua origem. $O$ programa funciona a partir de parcerias e busca a educação em turno integral, associando oficinas de cultura e esporte com atividades de reforço escolar. Adotou-se como conceito de cultura as manifestações culturais formalmente organizadas e institucionalizadas. No que diz respeito ao conceito de desenvolvimento, tomou-se como base as ideias de Furtado (1984), pensando-se o desenvolvimento como um conceito pautado em fins substantivos, e não apenas em fatores econômicos. A relação entre cultura e desenvolvimento é baseada em Santos (2008) e Furtado (1984), onde a cultura é fonte criativa para um processo endógeno de desenvolvimento. Foram coletados dados primários e secundários. Para sua análise, foram criados indicadores originários das categorias: cultura, desenvolvimento e a relação entre cultura e desenvolvimento. Há indícios de que o programa Bairro Escola não está mais funcionando da forma como foi planejado, principalmente por falta de recursos e de infraestrutura. Pode ser observada ainda uma diferença marcante entre o discurso dos entrevistados que trabalham nas escolas, e o discurso oficial. Indo ao encontro de Furtado (1984), o caso do Programa Bairro Escola ilustra que muitos obstáculos à liberdade criativa ainda precisam ser removidos para que a relação entre cultura e desenvolvimento se dê de forma plena.

Palavras-chave: Cultura. Desenvolvimento. Política cultural.

Artigo submetido em 10 de dezembro de 2010 e aceito para publicação em 22 de março de 2011.

1 Uma versão preliminar deste artigo foi publicada no IV Encontro de Administração Pública e Governança da ANPAD - ENAPG realizado em Vitória - ES no período de 28 a 30 novembro de 2010.

2 Mestranda em Administração Pública pela EBAPE/FGV. Endereço: Av. São Sebastião, 156 - 201, Urca, CEP 22291-070, Rio de Janeiro - RJ. E-mail: cristiane.costa@fgv.br

${ }^{3}$ Mestranda em Administração pela EBAPE/FGV. Professora no IFRJ/Campus Pinheiral. Endereço: Av. Nilton Penna Botelho, 500 401, CEP 27197-000, Pinheiral - RJ. E-mail: diana.costa.de.castro@gmail.com

4 Doutoranda em Administração pela EBAPE/FGV. Endereço: Estrada Francisco da Cruz Nunes, 3003, casa 26, CEP 24350-310, Piratininga, Niterói - RJ. E-mail: vanessabrulon@gmail.com

${ }^{5}$ Bacharelando em Administração pela EBAPE/FGV. Endereço: Rua São Clemente 96 - 301, CEP 22260-000, Botafogo - Rio de Janeiro /RJ. E-mail: marcelibmr@gmail.com 


\begin{abstract}
The objective of this paper is to identify how the current practice of the Program "Bairro Escola", from the city hall of Nova Iguaçu, in the State of Rio de Janeiro (Brazil), answers it's own stipulated development goals. This program works with partnerships with the Non Governmental Sector or others and the main objective is to offer full time education (in integral turn) by associate workshops of culture and sport with activities of school reinforcement. On this research we use the definition of culture as the cultural manifestations formal organized and institutionalized. The definition for development is based on Furtado (1984), where the development is shown as a concept based in substantive ends, and is not only about economic factors. The relation between culture and development is based on Santos (2008) and Furtado (1984), where the culture is a creative source for an endogenous process of development. We have collected primary and secondary data. For the analysis, it has been created indicators from the categories: culture, development and the relation between culture and development. It has indicate that the Program Bairro Escola is no long functioning like it has been planned, mainly due to have no resources and no infrastructure. A strong difference can be observed between the speech of the interviewed ones that work in the schools and the official speech. As Furtado said (1984), the case of the Program Bairro Escola illustrates that many obstacles need to be removed to the creative freedom conduce to a ideal relation between culture and development.
\end{abstract}

Keywords: Culture. Development. Cultural policy.

\title{
Introdução
}

As ações do Ministério da Cultura nos últimos anos, como a elaboração do Plano Nacional de Cultura e o Projeto Cultura Viva, evidenciam o engajamento do Brasil nas iniciativas difundidas mundialmente sobre a importância da cultura para o desenvolvimento dos países. Esse movimento internacional foi impulsionado principalmente pela ação da Organização das Nações Unidas para a Educação, a Ciência e a Cultura (Unesco), expressa na Convenção sobre a Proteção e Promoção da Diversidade das Expressões Culturais, em 2005. A preocupação crescente dos Estados com relação à cultura está acompanhada, também, de certa preocupação com a manutenção do patrimônio, entendido como direito e herança da humanidade e com a necessidade de preservação das especificidades locais. Esse cuidado é relevante face aos possíveis efeitos da globalização, como o risco de descaracterização de práticas tradicionais pela influência de agentes externos, ou de adaptações para atendimento das demandas de mercado.

Na abertura da Semana Nacional de Mobilização pela Cultura, realizada no Rio de Janeiro em setembro de 2009, o Ministro da Cultura, Juca Ferreira, destacou a atenção que a área tem recebido do Congresso Nacional. Ele refere-se às propostas que se apresentam atualmente, desde uma nova forma de articulação entre cultura, Estado e iniciativa privada, presente na proposta de reformulação da lei de fomento e incentivo à cultura, até a fixação de um percentual do orçamento para a cultura nos níveis federal, estadual e municipal, por meio da PEC $150^{6}$.

O aprimoramento dos indicadores culturais ${ }^{7}$ elaborados pelo Instituto Brasileiro de Geografia e Estatística (IBGE) e dos levantamentos sobre o setor cultural realizados pelo Instituto de Pesquisa Econômica Aplicada (IPEA), em ação conjunta com o Ministério da Cultura, somam-se aos esforços para a consolidação de

${ }^{6}$ Proposta de Emenda à Constituição para a fixação do orçamento para a cultura em $2 \%$ na União, 1,5\% nos estados e $1 \%$ nos municípios.

${ }^{7}$ Em 2006 o IBGE publica a primeira pesquisa do Sistema de Informação e Indicadores Culturais, que trata da sistematização dos dados coletados em pesquisas anteriores que estivessem relacionados direta ou indiretamente à cultura. Em seguida, insere em suas pesquisas um suplemento de cultura para coleta de dados sobre o setor cultural com o objetivo de investigar as condições da cultura nos municípios brasileiros (Munic - Cultura 2006). 
políticas culturais e para a garantia de recursos, a fim de que se estabeleçam modelos de gestão que, pelo menos, resistam às mudanças de governo. A sistematização dos dados permitiu observar fatores como as atividades, o número de empresas, os salários e a crescente participação do setor cultural na economia, além do mapeamento dos equipamentos, como museus, teatros e salas de cinema e da estrutura de gestão do setor cultural nos municípios.

Já no artigo publicado na Folha de São Paulo, em 2008, o então Ministro da Cultura Gilberto Gil reforçava a necessidade de entendimento da cultura como "um dos grandes ativos econômicos do país", pois "além de sua relevância simbólica e social, é capaz de gerar desenvolvimento". Dessa forma, destaca a relevância da economia da cultura, desde a produção até a promoção do acesso aos produtos e serviços culturais. Isso evidencia uma dificuldade na compreensão da relação entre cultura e desenvolvimento, que se dá tanto pela amplitude à qual pode estar relacionado o conceito de cultura, quanto pelo predomínio de uma concepção de desenvolvimento relacionada ao crescimento econômico.

Sugere-se que o conceito de cultura esteja "intimamente ligado às expressões da autenticidade, da integridade e da liberdade" das sociedades, como propõe Santos (2002, p.65). Esse enfoque sobre a cultura é relacionado neste trabalho com o conceito de desenvolvimento proposto por Furtado (1984), que parte do entendimento de que o indivíduo participa criativamente do processo cultural, transformando a sua realidade e gerando desenvolvimento por meio da realização de suas potencialidades.

Uma ação organizada que se apresenta como iniciativa de desenvolvimento com base na cultura é o Programa Bairro Escola, implementado no município de Nova Iguaçu, na Baixada Fluminense. O programa se realiza sob uma estrutura de relações entre o governo do município e os chamados parceiros, que são instituições locais que cedem espaços ociosos para a realização das atividades complementares.

A proposta geral do programa é de ampliação das possibilidades de aprendizado, por meio da experiência dos alunos no contato com os espaços e pessoas do bairro onde vivem e estudam, a partir de um conjunto de relações de parceria. Uma delas se dá entre o governo do município e os responsáveis por espaços disponíveis no bairro, como igrejas, clubes e outras instituições, a fim de que sejam realizadas as atividades oferecidas pelas escolas no contra-turno escolar. O programa conta também com a participação voluntária dos pais de alunos e com a contratação de estagiários e monitores que atuam nas oficinas e auxiliam nas demais atividades, como o trânsito dos alunos da escola até o parceiro, banhos e refeições. Conforme dados da Prefeitura de Nova Iguaçu, o programa é considerado central para gestão do Município, sendo integrado às ações das diversas secretarias. O programa é realizado em parceria com diferentes ministérios: o Ministério da Educação, por meio do programa o Mais Educação, o Ministério dos Esportes, com o programa Segundo Tempo e pelo Ministério da Cultura, por meio do programa Cultura Viva.

Essa iniciativa é de reconhecida relevância, dados os prêmios recebidos recentemente pelo Prefeito de Nova Iguaçu, como o Caixa Melhores Práticas em Gestão Local 2009/2010, sendo exemplo de expressão da relação entre cultura e desenvolvimento.

Tendo em vista que o Programa Bairro Escola parece uma unidade de observação adequada para a análise da relação entre cultura e desenvolvimento, o objetivo desse trabalho é identificar de que maneira as práticas atuais do Programa Bairro Escola atendem aos objetivos de desenvolvimento estipulados em sua origem.

${ }^{8}$ O Programa Mais Educação foi criado em 2007 para incentivo a atividades de educação complementar, por meio de parceria entre o Governo Federal e secretarias de educação estaduais e municipais. É subsidiado pelo Fundo Nacional de Desenvolvimento da Educação (FNDE). 


\section{Para Além de um Conceito de Cultura Relacionado ao Crescimento Econômico}

Como argumenta Porto (2004), há um grande desafio teórico no tema cultura e desenvolvimento, já que ele implica repensar o papel assumido pela cultura na vida política de uma sociedade. Como a cultura é muitas vezes tratada como um meio de solucionar problemas sociais e econômicos, a ligação entre cultura e desenvolvimento torna-se frequente, tanto na literatura especializada, como nos discursos oficiais de gestores públicos.

\section{Cultura}

A administração no Brasil apenas recentemente tem voltado atenção para a gestão da cultura. Esse movimento está impulsionado pela crescente participação da cultura na economia de muitos países e do desenvolvimento da chamada "indústria criativa", um dos setores que mais cresce na economia global, totalizando aproximadamente US\$ 1,3 trilhões em 2003, conforme dados do Banco Mundial (apud MDG-F, n.d, p.2). Para compreensão e operacionalização da cultura, são utilizados, conforme o interesse, diversos conceitos e delimitações, tais como indústria cultural, indústria criativa, economia da cultura, ou alguma das definições antropológicas ou sociológicas. Essa pluralidade dificulta a determinação do termo nas pesquisas e nas políticas culturais.

A criação do Fundo para Alcançar os Objetivos de Desenvolvimento do Milênio ${ }^{9}$ (MDG-F), das Nações Unidas, com um eixo temático sobre cultura e desenvolvimento, ilustra esse fenômeno no mundo. Com intenção de orientar os países em suas políticas culturais, o MDG-F divulgou um documento, dando ênfase à abordagem de indústria cultural e criativa, definindo os termos como segue:

"Cultural and Creative industries are understood in this context as those which comprise the formation, production, commercialisation, and distribution of cultural goods and services resulting from human inspiration and imagination. They include, among others, printing and publishing, visual and performing arts, cultural tourism and related heritage industries, cinema, music, radio, television and online industries, arts, and design and crafts." (MDGF, n.d, p.2).

Assim, a delimitação adotada abrange produtos e serviços culturais resultantes da inspiração ou imaginação humana. A definição é, no entanto, de difícil operacionalização na gestão. Mesmo diante dessa dificuldade, no Brasil a evolução das políticas públicas voltadas para a cultura têm se mostrado em acordo com essa lógica. Para o então Ministro da Cultura Gilberto Gil, cultura é vista em seu conceito mais amplo, como "dimensão simbólica da existência social de cada povo, argamassa indispensável a qualquer projeto de nação" (GIL, 2003, p.9).

Santos (2008) e Furtado (1984) alertam para os efeitos da cultura no Brasil contemporâneo. Para ambos, a cultura teria um papel a desempenhar, impulsionando e orientando o desenvolvimento do país em moldes que atendam às nossas necessidades e sejam oriundos do nosso povo. Nesse sentido, destacam-se dois

${ }^{9}$ MDG-F foi criado em 2006 e é um fundo das Nações Unidas de cooperação internacional para a aceleração do processo para logro dos objetivos de desenvolvimento do milênio, ou MDG, Millenium Development Goals. http://www.mdgfund.org/es/aboutus 
aspectos não excludentes: o primeiro, da cultura como um contramovimento para os efeitos danosos da globalização; e o segundo, da cultura com caráter funcionalista (MALINOWSKI, 1975)10.

Sobre os efeitos da globalização na cultura, Santos (2002) aponta que há um contra-movimento, que, a despeito das forças globalizantes e geradoras de uma mistura difusa, que ele chama "caldeada" de cultura, procura suas peculiaridades. Ainda segundo o autor, é a cultura autóctone que pode melhor utilizar os recursos, mesmo exógenos, para uma transformação ressignificada pelos seus códigos e necessidades.

A proposta da maioria dos órgãos nacionais e internacionais sugere a contemplação da visão mais ampla de cultura, mas pouco esclarece a respeito de como operacionalizá-la. Sabe-se que a cultura não se limita às organizações formais ou institucionalizadas, mas é nelas que a gestão se concretiza. Portanto, este trabalho adotará a delimitação de cultura como as manifestações culturais formalmente organizadas e institucionalizadas. Crê-se ganhar, nessa perspectiva, a possibilidade de inserir manifestações populares, e também construções científicas no entendimento de cultura, como sugere Santos (2002 e 2008), além das manifestações artísticas e criativas. Ainda que esse recorte apresente limitações, ele traz a possibilidade de compreender a gestão e suas potencialidades e contribuições nesse processo.

\section{Conceito de desenvolvimento}

O conceito de desenvolvimento foi sendo adaptado ao longo do tempo. Essas mudanças ocorreram tanto em relação à participação do Estado e do mercado e, mais recentemente, da sociedade civil organizada, quanto pela noção de crescimento econômico, que, se antes era confundida com o próprio conceito de desenvolvimento, hoje é compreendida como apenas uma das suas vertentes.

Celso Furtado, autor que contribuiu com ampla bibliografia sobre desenvolvimento e sua aplicação ao contexto brasileiro e latino-americano, apresenta dois sentidos distintos sobre a utilização do conceito: um relacionado aos avanços tecnológicos para ampliação da capacidade de produção e outro associado à satisfação das necessidades humanas (FURTADO, 2000). Ele defende que um sistema de produção mais eficaz não é suficiente para satisfazer as necessidades básicas da população, sobretudo quando são considerados os custos ambientais e sociais dessa prática, reforçando as desigualdades.

O autor critica processo de desenvolvimento de caráter mimético e dependente, ocorrido nos países identificados como periféricos em relação aos grandes centros econômicos, contra o qual propôs o modelo de desenvolvimento endógeno, baseado na substituição de importações para o fortalecimento do mercado interno. Para isso, indica a necessidade de entendimento do sistema de valores que orienta a aplicação das potencialidades criativas de uma sociedade (FURTADO, 2000). No contexto brasileiro, Furtado (1984, p.63) propõe que se pense o desenvolvimento "a partir de uma visualização dos fins substantivos que desejamos alcançar, e não da lógica dos meios que nos é imposta do exterior". E segue: "Desenvolver-se é ascender na escala de realização das potencialidades dos homens como indivíduos e como coletividade" (FURTADO, 1984, p.63).

Sachs (2005) relata a evolução do conceito de desenvolvimento, desde a fundação da teoria do desenvolvimento relacionada às ideias iluministas de progresso até a ampliação do conceito para além do aspecto econômico, passando a contemplar outras dimensões, como: social, política, cultural e ambiental.

${ }^{10}$ O Funcionalismo é uma corrente teórica com origem positivista (Herbert Spencer e Ėmile Durkheim), consolidada na antropologia por Bronislaw Malinowsk. O enfoque funcionalista conduz o pesquisador a entender toda a atividade social e cultural como funcional, ou seja, que desempenhe funções e seja indispensável naquela sociedade (MALINOWSKI, 1975). 
Sachs é consoante com Furtado ao propor que o foco do desenvolvimento é a satisfação das necessidades humanas autodefinidas.

Portanto, do ponto de vista teórico, parece superado o conceito de desenvolvimento puramente associado à ideia de crescimento econômico (GOULART, 2006; MISOCZKY, GOULART e MORAES, 2010; TRENNEPOHL et al., 2007). A noção de desenvolvimento passou a compreender questões como a sustentabilidade e a capacidade de promoção da realização das potencialidades humanas. Porém, na prática, observa-se ainda o enfoque sobre a dimensão econômica do desenvolvimento, mensurável, mesmo na área da cultura, por definição envolvida de aspectos substantivos. O Programa de Desenvolvimento da Economia da Cultura (Prodec), as linhas especiais do Banco Nacional do Desenvolvimento (BNDES) para a cultura e as leis de incentivo podem ser considerados mecanismos que estimulam a "empresarização" do setor cultural e enfatizam o potencial econômico da cultura.

Como aponta Furtado (2000), o desenvolvimento sobre aspectos da satisfação das necessidades humanas gera ambiguidades. Pode-se considerar que a ausência de objetividade dessa perspectiva seja dificilmente assimilada numa sociedade apoiada no sistema capitalista de produção e consumo. Mas desconsiderar os aspectos substantivos da cultura como elemento central para o desenvolvimento implica desconsiderar fatores como a continuidade dos projetos e a relevância para o público e comunidade envolvida. Além disso, as transformações sociais não escapam das consequências negativas dessa postura, como condições mínimas de segurança e sobrevivência, como alerta Canclini (1995).

Para Santos (2000), a expansão do modelo de desenvolvimento capitalista gera competitividade e a ausência de compaixão. Para o autor, "Consumismo e competitividade levam ao emagrecimento moral e intelectual da pessoa, à redução da personalidade e da visão do mundo, convidando, também, a esquecer a oposição fundamental entre a figura do consumidor e a figura do cidadão" (SANTOS, 2000, p.15).

\section{Por uma relação entre cultura e desenvolvimento}

A partir do que foi discutido anteriormente, evidencia-se a amplitude e a relevância dos conceitos de cultura e de desenvolvimento. Assim, a relação entre os conceitos herda essa dificuldade de consenso teórico. Apesar dos pontos de desacordo nos debates, a relação entre cultura e desenvolvimento é um tema central nas discussões contemporâneas, tanto no âmbito acadêmico quanto em experiências práticas (LOIOLA e MIGUEZ, 2007).

Em linhas gerais, pode-se distinguir entre autores que pensam a relação entre cultura e desenvolvimento a partir de uma perspectiva econômica e aqueles que adotam uma visão mais abrangente. Estes últimos buscam se afastar de uma visão instrumental, pensando não apenas em ganhos econômicos, mas priorizando os aspectos substantivos envolvidos.

$\mathrm{Na}$ abordagem econômica destacam-se autores como Reis (2007) e Lima (2007), que pensam os bens e serviços culturais como promotores do desenvolvimento. Essas leituras focam o conceito de economia da cultura. A partir desta perspectiva, a economia da cultura é vista como um caminho promissor para o desenvolvimento (REIS, 2007). Lima (2007) destaca o papel das atividades culturais na criação de empregos, geração de renda e atração de divisas, ressaltando a produção de bens culturais como uma importante área de investimento.

Em outra perspectiva encontram-se autores que pensam o desenvolvimento para além do seu aspecto econômico, e veem na cultura um elemento propulsor desse desenvolvimento mais amplo. Loiola e Miguez (2007), por exemplo, consideram a cultura como uma dimensão estratégica para o desenvolvimento, pensando este último como um desenvolvimento humano sustentável, que engloba outras dimensões da vida 
em sociedade. Sachs (2005) fala em uma cultura do desenvolvimento, que incentiva a participação no debate societal sobre um projeto para o país. Canclini (1995) defende que um desenvolvimento multicultural democrático só pode ser alcançado caso haja a possibilidade de expressão de diferentes culturas que estejam sujeitas mais ao interesse público coletivo do que à rentabilidade comercial. Para Canclini (1995), o Estado deveria assumir um papel de reconstrução do espaço público, para que nele os diversos agentes pudessem negociar acordos que desenvolvessem os interesses públicos. Complementando, Tomassini (1998) destaca a importância de fatores culturais para inúmeros aspectos do desenvolvimento, como a construção de identidades, os processos de socialização, bem como para a flexibilidade da sociedade.

Nesta discussão torna-se central o pensamento de Celso Furtado (1920-2004). A partir de críticas ao estilo de vida capitalista, o autor deixa clara a sua visão de que o desenvolvimento econômico é irrealizável e desvia a atenção das necessidades fundamentais da coletividade. Ainda, combate fortemente a generalização dos padrões atuais de consumo dos países ricos e defende a necessidade de uma reflexão sobre a cultura brasileira. Indo ao encontro de Furtado (1984), Santos (2002 e 2008) defende que a cultura protege as sociedades locais, regionais e nacionais contra ameaças de deformações que venham de fora. É como resultado deste processo de imposição de elementos da cultura de massa mostrado por Santos (2008), que o modelo de desenvolvimento dos países hegemônicos acaba sendo seguido pelos demais, sem que se considerem os aspectos culturais de cada país.

Furtado (1984, p. 30) entende o desenvolvimento "como reencontro com o gênio criativo de nossa cultura e como realização das potencialidades humanas". Desta forma, ele defende que, para que haja desenvolvimento, deve haver criatividade no plano político, que só é alcançada com elevada vontade coletiva. "A política de desenvolvimento deve ser posta a serviço do processo de enriquecimento cultural" (FURTADO, 1984, p. 32).

\section{Método}

No intuito de atender ao objetivo deste trabalho, foram realizadas pesquisas no campo, por meio de entrevistas semi estruturadas com Coordenadores Político-Pedagógicos de escolas de diferentes bairros do município de Nova Iguaçu. Assim, a coleta de dados primários para análise foi constituída das entrevistas, juntamente com observação documentada por fotografias das escolas, de parceiros e do entorno.

As pesquisas foram aplicadas nas seguintes escolas: Colégio Municipal Professora Irene de Oliveira (Bairro Vila de Cava); Escola Municipal Osiris Neves (Vila Operária); Colégio Municipal Rui Afrânio Peixoto (Bairro Miguel Couto); Escola Amazor Vieira Borges (Bairro Jardim Tropical); Colégio Darcy Ribeiro (Bairro Grama/Miguel Couto); e Colégio Janir Clementino (Bairro Miguel Couto). Além das entrevistas com coordenadores nas escolas, foram ouvidas três pessoas: o atual Coordenador de Oficinas, representando a Secretaria Municipal de Cultura de Nova Iguaçu; o professor Emílio Araújo, que participou da elaboração do Programa e atualmente publica uma série de relatos de oposição em blogs e outras mídias; e a diretora da Escola Livre de Cinema, que é uma ONG que atua como parceiro fundamental do Programa Bairro Escola.

Como dados secundários, foram utilizadas informações contidas e sistematizadas em Knopp (2008), no site da Prefeitura Municipal de Nova Iguaçu e da Escola Livre de Cinema, além de publicações relacionadas ao Programa. A Escola Livre de Cinema forneceu os dados de uma pesquisa de avaliação de resultados do projeto.

Para tratamento e análise dos dados, foram apontados indicadores em três categorias de análise: "cultura", "desenvolvimento" e "cultura e desenvolvimento". De posse da transcrição integral das entrevistas realizadas, operou-se a busca e sistematização dos trechos relevantes para a argumentação, de acordo com os 
indicadores de cada categoria. Foi realizada a análise interpretativa dos dados a partir dos indicadores e da base teórica revisada, bem como análise argumentativa (LIAKOPOULOS, 2004).

\title{
Bairro Escola, Cultura e Desenvolvimento
}

Foram destacados cinco indicadores para cada variável trabalhada. A análise a seguir é resultado da observação desses indicadores no campo.

\section{O Bairro Escola e a cultura}

Para analisar a variável cultura, foram destacados cinco indicadores, que são: a participação dos alunos em eventos culturais (fruição de arte e cultura); a participação em oficinas teóricas que discutam folclore ou arte e suas manifestações; a participação em oficinas práticas de folclore ou de arte (criação e produção); a participação em aulas de reforço escolar; e a participação em feiras científicas.

Em entrevista, o coordenador das oficinas culturais do projeto Bairro Escola afirma que as próprias oficinas têm mudado bastante. No início havia oficinas específicas das linguagens artísticas. Atualmente, para o que se chama primeiro segmento, que são as crianças de primeira a quarta série, o que se oferece são oficinas que abordam as artes e folclore de forma lúdica apenas, e em grupos segmentados por idade. O chamado segundo segmento, com crianças e adolescentes de quinta a oitava série, é inserido em oficinas que exploram mais especificamente as linguagens artísticas, dessa forma atendendo à participação em oficinas de folclore ou arte, onde não foi relatado se práticas ou teóricas por nenhum dos entrevistados, mas pelos exemplos dados pode-se supor que preponderantemente eram práticas.

\begin{abstract}
"As atividades culturais elas buscam essa coisa da experimentação. Porque a gente entende que não é o momento adequado, pedagogicamente, pra aprofundar nenhum tipo de técnica artística com as crianças, até porque é, é, a cultura, ela traz a expressão artística, mas ela não é oficina de arte, né, obviamente a gente traz elementos de arte, a gente tem sim, é... expressões de artes plásticas, de artes visuais, de audiovisual do teatro, da música, da dança, da cultura popular, mas tal como uma brincadeira popular é cultura pra gente, como às vezes, buscar dentro daquele bairro qual é a relação que ela tem com aquele espaço, com aquele tempo que ela teria, ocioso, se é a queimada, se é a amarelinha, dentro disso tem fatores culturais [...]". (Coordenador das oficinas culturais do projeto Bairro Escola)
\end{abstract}

No entanto as entrevistas nas escolas mostram uma realidade diferente. Das escolas visitadas, apenas a Escola Livre de Cinema (o projeto de uma organização não governamental que é parceira), que atende prioritariamente aos alunos da escola municipal Janir Clementino, declara estar com as oficinas de cultura (vídeo) funcionando. Há relatos de outras escolas que tiveram oficinas de cultura, e são ainda mais frequentes relatos de que muita coisa foi prometida aos pais e à escola, mas, na realidade, poucas opções são efetivamente ofertadas. Quando perguntada sobre situações de conflito na implementação do projeto, uma explica que:

"[...] no começo é que houve [conflito] por conta disso, que assim, os moldes do Bairro Escola, quando foi apresentado, foi uma coisa, e aí quando começou, foi outra, né? Por exemplo, quando iniciou, antes de iniciar, a gente teve toda aquela: olha, vai ter natação, vai ter balé, vai ter isso, né, quando foi feita a reunião com os pais, e aí, depois, quando eles viram que aí não foi totalmente, é, explicado que teria a natação, teria balé mas desde que a 
escola tivesse parceiros próximos, que disponibilizassem os espaços." (Diretora do Colégio Municipal Professora Irene de Oliveira)

A mesma diretora afirma que a evasão ao projeto aconteceu porque as oficinas de cultura acabaram, e as de esporte também. Só ficaram as oficinas de reforço escolar. Os motivos apontados por unanimidade, para que as oficinas tivessem acabado, foram a falta de estagiários e de parceiros, mas ninguém sabe explicar exatamente por que os estagiários diminuíram drasticamente. As especulações versam sobre a falta de verba para pagar os estagiários ou os parceiros, que seriam os oficineiros. O despreparo dos estagiários para lidar com as turmas foi relatado também pelas diretoras e coordenadoras do programa, assim como o elevado índice de faltas: "eu tinha vinte [estagiários] de aprendizagem no total. Hoje eu tenho seis de aprendizagem, aí cultura são... duas meninas, antes devia ser mais ou menos uns dez estagiários de cultura" (Coordenadora Político-Pedagógica do Colégio Municipal Rui Afrânio)

Todos os entrevistados demonstram acreditar muito no projeto e falam com eloquência e entusiasmo sobre as coisas que ouviram dizer que aconteceram ou que vão acontecer em outras escolas. Na escola Osíris Neves, onde não há oficinas de cultura para o segundo segmento, o depoimento foi esperançoso a respeito do recurso federal que poderá ser destinado à escola pelo projeto Mais Educação, e será usado como se fosse do Bairro Escola:

"É só reforço, por enquanto, ainda não, tá, nós estamos esperando a verba do Mais Educação pra tá oferecendo rádio, jornal, banda, dança, hip hop, essas coisas, tudo isso vai ser oferecido pra esses alunos, por enquanto, eles só estão fazendo português e matemática e estão fazendo esporte com o Segundo Tempo [...]". (Coordenadora Político-Pedagógica da Escola Municipal Osíris Neves)

O Segundo Tempo é outro programa com repasse de recurso Federal que é incorporado e tratado como atividade do Bairro Escola por todas as escolas e pela prefeitura. Percebemos nessa mesma escola mais um programa de auxílio federal que impacta em cultura por meio de incentivo à leitura, no espaço chamado de "mesa do Positivo". Ainda assim, cabe salientar que a leitura é um esforço de alfabetização e não de fruição, discussão teórica ou produção de arte literária: "aqui é a mesa do Positivo, essa... esses computadores são utilizados mais com os alunos do primeiro ao quinto ano é... pra trabalhar reforço, alfabetização, softwares educativos" (Coordenadora Político-Pedagógica do Colégio Municipal Rui Afrânio). Ela ressalta, ainda, que os computadores não funcionam bem, não podem ser ligados em rede e que a escola ganhou outros computadores do Programa Nacional de Tecnologia Educacional (Proinfo), mas que eles não são usados porque a verba do Plano de Desenvolvimento da Escola (PDE), para montar a estrutura necessária, não chegou. Quando perguntada sobre o público que frequenta o Bairro Escola, ela corrobora a fala do Coordenador das Oficinas de cultura, que diz que o perfil ainda é de alunos carentes, e cuja alternativa seria pior do que enfrentar a precariedade em que se encontram as escolas, a alimentação e as atividades do programa.

Para ficar na escola os dois turnos, a criança precisa de alimentação, de água, precisa tomar banho, e há relatos de escolas que não dispõem de chuveiro, ou dispõem de apenas um chuveiro para 200 crianças, o que resulta em banhos de mangueira (Escola Municipal Osiris Neves), e de falta de merenda (Colégio Darcy Ribeiro) e até de água potável para atender ao contingente duplicado pelo horário integral. A falta de recursos para as atividades básicas, como escovas de dente e toalhas, é evidenciada em todas escolas municipais pesquisadas. A respeito da reação dos alunos mais velhos ao esquema do projeto é interessante na fala da coordenadora do Colégio Rui Afrânio, sobre uma pesquisa que "eles fizeram", mas ela não viu, dizendo que os alunos não gostam de ficar na escola, tomar banho e sair em fila para o parceiro, então a proposta era que: 
"[...] esses horários vagos fossem ocupados com as outras oficinas, escola de cinema, com música, essas coisas, só que a nossa escola não tem nada disso ainda, teve uma oficina de música, de dança, essas coisas, no ano passado teve repercussão, mas acabou, não voltaram esse ano, não sei por quê, eu tô esperando o Mais Educação e os Pontinhos de Cultura." (Coordenadora Político-Pedagógica do Colégio Municipal Rui Afrânio).

Para a coordenadora da Escola Municipal Amazor Vieira Borges, os coordenadores do Projeto das oficinas de cultura "eles têm intenção de integrar o bairro e a escola, todas as informações é... cultura, todo tipo de trabalho manual, todo tipo de artesanato, esse seria o objetivo central do Bairro Escola, só que na verdade não é assim que acontece", e conclui: "Deveria ser assim".

Há relatos de que as oficinas de cultura foram mais diversificadas antes, atendendo melhor ao indicador de participação em oficinas práticas de cultura efetivamente.

\begin{abstract}
"Tinha a questão da cultura é a seguinte é... capoeira é uma dança, assim, popularmente muito querida, todas as crianças gostariam de aprender, (pausa) a dança (pausa), as crianças também gostavam e ajudavam a gente, pedagogicamente, como? Coordenação motora [...] A gente incentivava também a questão da leitura escrita com a parte de teatro, nós tivemos um ano de oficina de teatro." (ex-coordenador do Colégio Darcy Ribeiro)
\end{abstract}

Ainda assim, fica evidente nessa fala e na de outros coordenadores, como do Colégio Rui Afrânio, que as oficinas de cultura serviam prioritariamente para melhorar o desempenho escolar, e não para ensinar a cultura. De diversas formas a mensagem fica subentendida, inclusive na fala do coordenador das oficinas de cultura, como se verá mais adiante.

Emilio, ex-subsecretário de cultura do início do projeto Bairro Escola, diz, a respeito de cultura, que a criação de possibilidades de uso do espaço é relevante no contexto de Nova Iguaçu, explicando que a cidade não tem praças ou espaços públicos, então essa criação traz possibilidades "independentemente de qualquer coisa, isso é positivo, porque você tá oferecendo serviços, políticas, que não existiam antes".

As atividades desenvolvidas nas oficinas de cultura não contemplam em nenhum dos relatos a fruição e contato com manifestações artísticas consagradas. Tal fato ganha mais relevância quando se entende que a cidade quase não oferece essas possibilidades nem em situações fora da escola porque há uma carência de equipamentos de cultura de todos os tipos. Por isso entende-se que elas se limitam a atividades que são mais lúdicas do que culturais. Indagada sobre o que acontece nas oficinas de cultura, a resposta foi:

"[...] eles fizeram uma época, né, (pausa) tentando resgatar coisas do bairro (pausa) é valorizar o bairro, pesquisar... por que essa rua tem o nome [...] aí eles fizeram a pesquisa, aí depois vamos descobrir porque que tem esse nome [...] essas coisas, assim, de resgate do bairro as profissões, eles saíram daqui, eles fizeram uma atividade, eles foram conversar com o dono da peixaria, por que ele é... abriu a peixaria, se ele gostava da profissão [...]". (Coordenadora Político-Pedagógica do Colégio Municipal Rui Afrânio).

A mesma coordenadora relatou uma atividade em que os alunos saíram com o pessoal da cultura "pelas ruas, falando com os moradores sobre a campanha que a escola tá recolhendo a caixinha com a finalidade da gente tá cobrindo a quadra" (Colégio Municipal Rui Afrânio). Ela justifica que os alunos do horário integral fizeram isso porque já tinham autorização para saírem para a rua então era mais fácil, e que com a arrecadação a escola ganhou três telhas. A despeito das telhas, nenhum ganho em cultura foi mencionado, muito embora essa atividade tenha sido parte das oficinas.

A participação em feiras científicas não foi sequer mencionada, e os únicos eventos relatados, envolvendo mais escolas, foram os campeonatos esportivos promovidos pelo programa Segundo Tempo. O indicador 
participação em oficinas de cultura teóricas não foi encontrado nas entrevistas nem observado nas visitas, mas como não houve relato detalhado de todas atividades desenvolvidas por todos os estagiários, é possível que isso não indique a ausência desse indicador no campo.

\section{O Bairro Escola e o desenvolvimento}

Para verificação das práticas atuais em relação ao processo de desenvolvimento proposto originalmente no programa Bairro Escola, foram analisadas as entrevistas e documentos a partir de seis indicadores: desempenho escolar, consciência cidadã, qualidade de vida, infraestrutura da escola, infraestrutura do bairro e geração de emprego e renda.

De acordo com os dados do Inep sobre o Índice de Desenvolvimento da Educação Básica (Ideb), houve um aumento no índice da rede municipal de ensino de Nova Iguaçu de 3.6, em 2005, para 4.0, em 2009, correspondendo à meta para o ano na $4^{\mathrm{a}}$ série $/ 5^{\circ}$ ano. Para o Coordenador de Oficinas do Bairro Escola, $\mathrm{o}$ melhor desempenho é reflexo das ações do programa: "na última avaliação do Ideb, a gente já tinha dois anos de Programa Bairro Escola, a gente teve um aumento significativo no Ideb de quase todas as escolas que a gente tem programa de educação integral" (Coordenador de Oficinas). Porém, conforme os dados do Inep sobre o Ideb (Tabela 1 e Tabela 2), apenas uma das escolas visitadas durante a pesquisa de campo superara, ainda que numa margem pequena, a meta para o ano de 2009.

Tabela 1

IDEB - 4a série/5 ano

\begin{tabular}{|l|c|c|c|c|c|}
\hline Escola & $\mathbf{2 0 0 5}$ & $\mathbf{2 0 0 7}$ & $\mathbf{2 0 0 9}$ & Meta 2007 & Meta 2009 \\
\hline Ruy Afrânio Peixoto & 3.5 & 4.2 & 3.5 & 3.5 & 3.9 \\
\hline Osires Neves & 3.9 & 4.0 & 4.0 & 3.9 & 4.3 \\
\hline Darcy Ribeiro & 3.6 & 3.5 & 4.1 & 3.7 & 4.0 \\
\hline Irene da Silva Oliveira & 3.7 & 3.9 & 4.2 & 3.8 & 4.1 \\
\hline Amazor Vieira Borges & 3.9 & 4.1 & 4.1 & 4.0 & 4.3 \\
\hline
\end{tabular}

Fonte: (sistemasideb.inep.gov.br)

Tabela 2

IDEB - 8a série/9a ano

\begin{tabular}{|l|c|c|c|c|c|}
\hline Escola & $\mathbf{2 0 0 5}$ & $\mathbf{2 0 0 7}$ & $\mathbf{2 0 0 9}$ & Meta 2007 & Meta 2009 \\
\hline Janir Clementino & 3.6 & 4.0 & 3.6 & 3.6 & 3.8 \\
\hline
\end{tabular}

Fonte: (sistemasideb.inep.gov.br) 
Verificou-se também que, ainda conforme o Inep, o índice manteve-se em 3.5 para a $8^{\mathrm{a}}$ série $/ 9^{\circ}$ ano, abaixo da meta para 2009, que era de 3.7. Os coordenadores do Colégio Janir Clementino, que trabalhou apenas com o $2^{\circ}$ segmento, destacam a preferência dos alunos pelas atividades culturais e esportivas, em detrimento das tarefas de reforço das disciplinas.

Já quanto ao indicador referente à promoção da consciência cidadã, observou-se que o projeto busca influenciar o comportamento dos sujeitos da comunidade, como comerciantes, motoristas e pais de alunos:

"A educação ultrapassa os limites da aprendizagem. Tudo começa com o surgimento de parceiros, como um clube, por exemplo. Eles cedem seus espaços físicos que não estão sendo usados durante o dia para abrigar aulas de vôlei, natação ou recreação. Toda a comunidade é convidada a se juntar ao professor na tarefa de educar: agentes de trânsito, pessoal da limpeza, motoristas, comerciantes, moradores e, principalmente, os jovens." (site Prefeitura de Nova Iguaçu)

Além disso, os alunos, ao deslocarem-se pelo bairro, tomariam conhecimento da sua própria realidade:

"[...] fazendo esse trajeto até o parceiro, ou os parceiros, porque têm casos que são mais de um, então já seria uma forma de educar essas crianças. Estariam participando do bairro, vendo como é o bairro, o entorno do bairro, o quê que tem, o quê que não tem, o quê que precisaria melhorar, então seria uma forma também de você tá levando a educação pra, né, passando dos muros da, da escola". (Diretora e Ex-Coordenadora de Aprendizagem, Colégio Municipal Irene da Silva Oliveira).

No entanto, por falta de profissionais, o programa está suspenso nesse colégio.

A diretora da Escola Livre de Cinema relata a experiência com os alunos do Programa, que tomam o dia a dia como temática central dos documentários produzidos:

[...] em 2006 nós já conseguimos criar vários documentários, saiu o documentário porque... "uma ida ao banco", que era uma questão dos alunos, temáticas que saiam deles mesmo, porque que esses alunos...muitos deles nunca tinham entrado no banco, Nova Iguaçu naquela época...Miguel Couto naquela época só existia um banco, que era o HSBC, então, ir ao banco ainda era um passeio, né, e isso era uma demanda deles "ah ,queria conhecer o banco, queria ver como cospe dinheiro e tal, a máquina” tentamos entrar no banco, não conseguimos, apesar de toda interferência pública pra pedir ao banco pra ter esse acesso, eles não permitiram, mas mesmo assim os alunos filmaram a tentativa de entrar, fizemos temas sobre por que tanta pastelaria, né, aqui em Miguel Couto...". (Diretora da Escola Livre de Cinema)

Destaca-se, na proposta originalmente apresentada, a previsão de reuniões periódicas em conselhos, como importante instrumento de participação da comunidade no processo de aperfeiçoamento do Programa Bairro Escola (KNOPP, 2008), porém, conforme relato de alguns coordenadores, essas reuniões têm sido realizadas: "olha, a comunidade escolar, eles não são muito de participar, não" (Diretora e Ex-Coordenadora de Aprendizagem, Colégio Municipal Professora Irene da Silva Oliveira). É relatada também a dificuldade de contato até mesmo com a Secretaria de Educação, onde os coordenadores lembram que antes havia visitas na escola de alguém da Secretaria, e atualmente para tudo é preciso ir até a SEMED na secretaria, "então, antes era mais fácil, assim, é... pelo menos uma vez na semana a gente tinha aquele profissional que vinha [...] hoje a gente sente falta dessa... desse profissional que não tem, por conta da mudança da gestão" (Coordenadora Político-Pedagógica da Escola Ruy Afrânio Peixoto) 
Quanto ao indicador de melhoria da qualidade de vida, dadas as dificuldades enfrentadas no dia a dia pela maioria das crianças que participam do Programa, apresenta-se um relato que fala do início do programa, com oferta de mais refeições diárias nas escolas e, em alguns casos, o banho das crianças:

\begin{abstract}
"Questão de alimentação, perfeito, que... queijo minas, pão integral, alimentação é foi bem bacana é questão de atender, né, as crianças que fazem natação, faz capoeira, tem muito mais fome e por ser... pela escola ser uma área extremamente precária economicamente, muitas vezes, as crianças não tinham comida em casa." (Ex-Coordenadora Político Pedagógica da Escola Darcy Ribeiro)
\end{abstract}

O que foi visto nas outras escolas atualmente contradiz essa realidade, como as dificuldades para manutenção de atividades básicas, como relata a Coordenadora Político-Pedagógica da Escola Ruy Afrânio Peixoto. Há problemas com a falta de água e de merenda, também no relato da coordenadora do projeto no Colégio Janir Clementino.

Foram apontadas melhorias na capacidade de percepção sobre a vida, elemento importante na definição de desenvolvimento apresentada por Furtado (1984), e no desempenho escolar dos alunos. Uma excoordenadora relata que percebe "um crescimento muito grande de pessoa, de conscientização de que ela pode mudar o ambiente em que vive, que ela pode produzir para viver melhor a questão da sustentabilidade, ganho também em questões educacionais... (Ex-Coordenadora Político-Pedagógica da Escola Darcy Ribeiro)

No que se refere à infraestrutura disponível na escola para a realização das atividades do Programa, destacam-se os relatos sobre o estado precário em que se encontram, desde os fogões, necessários à elaboração das refeições dos alunos, até os equipamentos de informática, como destacou a Coordenadora Político-Pedagógica do Colégio Municipal Osiris Neves.

Já quanto à infraestrutura do bairro, poucos conservam as pinturas e placas de identificação do programa e para acesso dos alunos aos parceiros. Outra queixa recorrente dos coordenadores foi relacionada à dificuldade de atuação junto aos parceiros. Muitos deles desligaram-se das escolas já no início das atividades, pois não receberam o apoio necessário da Prefeitura para a manutenção de suas instalações.

Com relação ao indicador de geração de emprego e renda, destacam-se as possibilidades de trabalho, mesmo que temporário, nas atividades de estágio nas oficinas e como monitores para acompanhamento das crianças no trajeto entre a escola e o parceiro. A formação possibilitada pela Escola Livre de Cinema também se apresenta como uma possibilidade de ganhos futuros para os jovens participantes:

"[...] a gente mostra resultado, a gente tem uma demanda muito grande de alunos e de trabalho [...] É a prefeitura também, ela busca muito é... incentivar a gente, pra gente multiplicar nosso conhecimento, nosso saber e ela, o que que ela faz? Ela traz monitor, ela traz professores pra se qualificarem aqui, ela traz estagiários pra se qualificarem aqui, pra dar qualidade a outras oficinas e consequentemente o Bairro Escola." (Diretora da Escola Livre de Cinema).

A partir da análise dos relatos referentes aos indicadores pesquisados, observa-se que são muitas as dificuldades encontradas para a manutenção do programa nas escolas, principalmente quanto à infraestrutura disponível, tanto nas escolas quanto no bairro, e pela falta de investimentos necessários à manutenção das atividades. Destaca-se como ponto positivo e convergente ao conceito de desenvolvimento adotado neste estudo, a partir da perspectiva de Furtado (1984), o relatado quanto à formação por meio do programa, na afirmação de que contribui para a ampliação da capacidade do aluno em se perceber como cidadão consciente de seu papel no mundo. 


\section{O Bairro Escola e a relação entre cultura e desenvolvimento}

Com base nos dados coletados por meio de entrevistas e de documentos, será analisada a relação entre cultura e desenvolvimento no programa Bairro Escola a partir dos seguintes indicadores: a utilização de traços culturais/peculiaridades da região no desenvolvimento de projetos sociais; melhoria na formação dos indivíduos, capacitando-os para o mercado de trabalho; o incentivo à participação da comunidade na construção do projeto; desenvolvimento local em decorrência dos recursos trazidos pelas atividades culturais do programa; a presença de fatores culturais contribuindo para a construção de identidades; o incentivo à liberdade criativa dos participantes dos projetos.

No que se refere à utilização de traços culturais/peculiaridades da região no desenvolvimento de projetos sociais, observa-se que há uma preocupação por parte dos formuladores dos projetos que compõem o programa em utilizar alguns traços culturais daquela região em seu desenvolvimento. Este fato se mostrou presente no depoimento do coordenador de oficinas, que corresponde ao discurso oficial, bem como no discurso de pessoas diretamente envolvidas na implementação do projeto.

"[...] buscar dentro daquele bairro qual é a relação que ela tem com aquele espaço, com aquele tempo que ela teria, ocioso, se é a queimada, se é a amarelinha, dentro disso tem fatores culturais, buscar as representações dentro dos bairros, né, ficar enaltecendo isso, quem é que conta a história naquele bairro, quem é que não conta a história mas tem história naquele bairro, vira personagem daquele bairro, então as atividades culturais no primeiro segmento vêm trabalhando um pouco isso." (Coordenador de Oficinas).

Executado em uma escola, o projeto Meu Livro Minha Vida "que era as crianças contando a história do bairro antes da escola, foi é... muito interessante, porque eles se reconheceram enquanto movimentadores e modificadores daquele lugar" (Ex-coordenador do Colégio Darcy Ribeiro), ilustra o indicador, assim como o projeto Caça ao Bairro que "já entra cultura que cada equipe vai procurar no bairro uma atividade que ela ache interessante, a... vai procurar o senhor mais antigo do bairro e vai contar a história do bairro, a outra equipe vai procurar é... o que eles acharem mais interessante" (Coordenadora Político-Pedagógica do Colégio Amazor Vieira Borges). Os elementos presentes nestes discursos vão ao encontro de Furtado (1984), que defende que o desenvolvimento deve se dar com base na cultura da região, demonstrando a presença da relação entre cultura e desenvolvimento no Bairro Escola.

No que diz respeito à melhor formação dos indivíduos para que estes se tornem capacitados para o mercado de trabalho, tal fato foi destacado de diferentes formas pelos entrevistados. Segundo o coordenador de oficinas "em Nova Iguaçu muitos pais dependem de tar com seu filho ocupado, enquanto eles acham que seu filho tá ocupado, a gente tá criando a formação do cidadão, para trabalhar, para ganhar o seu dinheiro" (Coordenador de Oficinas). Da mesma forma, essa ideia também se mostrou presente no discurso de alguns coordenadores que atuam nas escolas, como no depoimento que se segue:

"[...] e isso é muito importante pra eles, porque eles se veem valorizados, eles pegam uma expectativa de vida que eles não tinham, a gente pegou um aluno que trabalhava no sinal porque a mãe obrigava, foi jogar futebol, está hoje numa escolinha de futebol tem grande chance de... de ser alguém e é disso que eles precisam, incentivo pra ser alguém." (Excoordenador do Colégio Darcy Ribeiro)

Outros elementos representantes desta relação, entretanto, apesar de se mostrarem presentes no discurso oficial, foram contrariados no depoimento dos entrevistados diretamente envolvidos na implementação do Bairro Escola. Este é o caso do incentivo, por parte dos formuladores dos projetos, à participação da população de Nova Iguaçu na elaboração e execução dos projetos. No discurso oficial, tal fato se mostrou presente, e pode ser representado por informações que constam no site de Nova Iguaçu, como a afirmação de 
que o programa "funciona com o apoio da comunidade escolar, dos pais, de organizações sociais e institutos e tem a participação de mães voluntárias, estudantes universitários, monitores e parceiros, somando mais de quatro mil pessoas diretamente envolvidas". Este elemento pode ser ainda representado pelo discurso do coordenador de oficinas, ao afirmar: "agora dos parceiros, os parceiros são da comunidade, né? A gente bate na porta, a gente bota todo mundo da escola pra se envolver, a gente faz a reunião com os pais, pra que eles indiquem" (Coordenador de Oficinas).

Não obstante a indicação de que há uma efetiva participação da comunidade no programa, principalmente por meio das parcerias, o discurso daqueles que participam da implementação do projeto contradiz esta informação. Um problema relatado na maioria das entrevistas é a dificuldade de as parcerias se estabelecerem e se manterem. Tal fato pode ser ilustrado pela fala do coordenador de uma escola, que afirma: "a questão da parceria que é um problema que acontece até hoje, onde nós perdemos a parceria com a igreja e... aí só temos o salão de festas, então hoje o horário integral funciona na escola..." (Coordenadora Político-Pedagógica da Escola Ruy Afrânio Peixoto)

Desta forma, o envolvimento da comunidade de Nova Iguaçu nos projetos é questionável, não apenas no que diz respeito à comunidade de forma geral, mas também em relação aos diretamente interessados no programa, como os pais dos estudantes. A importância deste envolvimento para a relação entre cultura e desenvolvimento é ressaltada por Sachs (2005) e Furtado (1984), mas parece não estar presente no programa objeto de estudo.

Em relação ao desenvolvimento local em decorrência dos recursos trazidos pelas atividades culturais do programa, essa discrepância entre os discursos é ainda mais marcante, já que os envolvidos diretamente na rotina diária das escolas defendem que o pouco investimento que se fez já está se deteriorando. Por um lado, no depoimento do coordenador de oficinas, houve forte defesa da existência de melhorias diretas para a região trazidas pelo Bairro Escola "a gente pensa obras e pensa a questão do entorno da escola, né, se a criança vai se deslocar pela cidade, ela precisa de intervenção urbana, ela precisa que o passeio 'teja' melhorando, ela precisa que a rua esteja em melhores condições".

Mais uma vez, este discurso é contrariado pelos dados coletados: "então acho que, assim, falta um pouquinho da estrutura..." (Diretora do Colégio Municipal Professora Irene de Oliveira). Ou de forma ainda mais direta: "A primeira ideia era construir escolas. Bem, o Lindberg não construiu até hoje, em cinco anos de governo, é, nós estamos no quinto ano, né, ele não construiu nenhuma escola, ele reformou mal e porcamente algumas" (Emílio Araújo).

No que diz respeito à presença de fatores culturais contribuindo para a construção de identidades, este fator só se mostrou presente no discurso oficial, representado pela entrevista do coordenador de oficinas, e por isso não se pode considerar que ocorre na prática. Já o incentivo à liberdade criativa dos participantes dos projetos, não foi mencionado em nenhuma das entrevistas e por isso não pode ser analisado.

\section{Conclusão}

O Programa Bairro Escola surge como uma política que seria aplicada nas escolas municipais, em parceria com a comunidade, expandindo o período de tempo na escola com objetivo de aliar cultura e desenvolvimento. No entanto pode-se perceber pela análise dos dados que o programa sofreu mudanças estruturais grandes, tanto no que tange ao apoio dado às escolas, parceiros e entorno quanto aos seus próprios métodos e metas, distanciando-se paulatinamente dos objetivos iniciais. Pode-se observar que muitas ações que ainda permanecem nas escolas são financiadas por outros programas federais, incorporados ao discurso do programa municipal, a exemplo do Segundo Tempo e Mais Educação. 
Conclui-se que o programa não está funcionando mais como planejado e que ultimamente sofre com reduções drásticas de recursos, estruturas e de articulação política. Diferente do que foi observado em Knopp (2008) e relatado por entrevistados, o programa goza de pouca relevância na cena política municipal mesmo antes de o atual prefeito (suposto mentor do Bairro Escola) se afastar do cargo para candidatar-se ao Senado Federal. No entanto, é clara a diferença no discurso a respeito da realidade das ações dos entrevistados de dentro das escolas e o discurso oficial, que alega que o programa funciona melhor do que antes e que continua sendo a prioridade do governo.

Os problemas do programa Bairro Escola, principalmente no que diz respeito à falta de recursos, são ressaltados inúmeras vezes. Mesmo diante desse cenário, entretanto, o apego dos entrevistados ao programa é demonstrado inúmeras vezes, acompanhado de uma esperança de que o Bairro Escola ainda possa funcionar. Para todos os entrevistados o programa tem potencial para dar certo. É ainda com grande dificuldade que alguns profissionais levantam críticas ao programa. Mesmo diante dos problemas, ainda é mantida a crença inicial de que o Bairro Escola traz um grande progresso para a comunidade de Nova Iguaçu.

Uma significativa parte dos indicadores não foi encontrada no campo, conduzindo à possível conclusão de que o programa não atende à premissa de ser uma política que de fato consegue utilizar a cultura como fator desencadeador de desenvolvimento, em seu mais amplo sentido. Entretanto, inferiu-se uma peculiaridade a partir da observação de que ainda há uma percepção generalizadamente positiva do programa pelos atores envolvidos. Aqueles que trabalham diretamente com o Bairro Escola ainda acreditam no programa, e defendem que este pode dar certo, não obstante os problemas que existem hoje. Mesmo ao levantar as dificuldades enfrentadas, os entrevistados justificam-se e argumentam que isto não é um indicativo de fracasso. A consolidação desta imagem positiva demonstra que os supostos objetivos políticos do Bairro Escola já foram atingidos. Esses objetivos julgados "eleitoreiros" pela crítica feita por um dos entrevistados podem ser compreendidos como parte integrante do jogo político. Assim, a inferência pode contribuir para os estudos da gestão pública ao indicar que, ao contrário do que é costumeiramente relatado, um programa pode sobreviver a uma mudança de partidos, pelo menos no imaginário dos atores no campo. Por outro lado, a constatação pode justificar o abandono do programa por parte do governo municipal, uma vez que o objetivo velado de criar uma imagem positiva foi atingido, a despeito do objetivo divulgado que é conduzir ao desenvolvimento local por meio da cultura.

Assim, parece que políticas públicas desse tipo ainda têm muitos desafios a enfrentar, principalmente no que diz respeito à interferência de objetivos adversos no processo. Indo ao encontro de Furtado (1984), fica claro que muitos obstáculos à liberdade criativa ainda precisam ser removidos para que a relação entre cultura e desenvolvimento se dê de forma plena, como ilustra o caso do Programa Bairro Escola.

\section{Referências}

CANCLINI, N. Consumidores e cidadãos: conflitos multiculturais da globalização. Rio de Janeiro: UFRJ, 1995.

Reconstruir políticas de inclusão na América Latina. In: UNESCO. Políticas Culturais para o desenvolvimento: uma base de dados para a cultura. Brasília: Unesco, 2003. p. 21-38.

COELHO, T. Dicionário crítico de política cultural: cultura e imaginário. 3 ed. São Paulo: Iluminuras, 2004.

FURTADO, C. Cultura e desenvolvimento em época de crise. Rio de Janeiro: Paz e Terra, 1984.

O mito do desenvolvimento econômico. 4 ed. Rio de Janeiro: Paz e Terra, 1996. 
Introdução ao desenvolvimento - enfoque histórico-estrutural. 3ed. Rio de Janeiro: Paz e Terra, 2000.

GIL, G. Apresentação. In: UNESCO. Políticas Culturais para o desenvolvimento: uma base de dados para a cultura. Brasília, DF: UNESCO.

GOULART, S. Uma abordagem ao desenvolvimento local inspirada em Celso Furtado e Milton Santos. Cadernos EBAPE.BR. $\quad$ v. 4 4, n. $3 . \quad$ Out. $2006 . \quad$ Disponível em: <http://www.ebape.fgv.br/cadernosebape/asp/dsp_lst_artigos_edicao.asp?coded=42>. Acesso em: 29 jun.2010.

KNOPP, G. Cultura e desenvolvimento local: um estudo do Programa Bairro Escola da cidade de Nova Iguaçu. Dissertação (Mestrado em Administração Pública) - Escola Brasileira de Administração Pública e de Empresas da Fundação Getulio Vargas (EBAPE/FGV), Rio de Janeiro, 2008.

LIAKOPOUlOS, M. Análise Argumentativa. In: BAUER, M. W.; GASKELL, G. Pesquisa Qualitativa com Texto, Imagem e Som: um manual prático. 3ed. Petrólpolis - RJ: Vozes, 2004.

LIMA, C. Políticas culturais para o desenvolvimento: o debate sobre as indústrias culturais e criativas. In: ENCONTRO DE ESTUDOS MULTIDISCIPLINARES EM CULTURA, 3. 2007, Salvador. Anais... Salvador: ENECULT, 2007.

LOIOLA, E.; MIGUEZ, P. Sobre cultura e desenvolvimento. In: ENCONTRO DE ESTUDOS MULTIDISCIPLINARES EM CULTURA, 3. 2007, Salvador. Anais... Salvador: ENECULT, 2007.

MALINOWSKI, B. A Teoria Funcional. In: Uma teoria científica da cultura. Rio de Janeiro: Zahar, 1975.

MDG-F. Thematic window terms of reference - culture and development. Terms of reference for thematic window on culture and development. N.d.

MISOCZKY, C., GOULART, S., MORAES, J. A ditadura do discurso do desenvolvimento em questão: das críticas proscritas a concepções emergentes. In: ENCONTRO DA DIVISÃO DE ESTUDOS ORGANIZACIONAIS DA ANPAD, 9., 2010. Florianópolis. Anais... Florianópolis: ENEO, 2010. CD-ROM.

ORTIZ, R. Cultura e desenvolvimento. In: CAMPUS EUROAMERICANO DE COOPERAÇÃO CULTURAL, 5, 2007. Almada - Portugal. Anais Eletrônicos... Almada - Portugal: CEC, 2007. Disponível em: <http://www.redculturalmercosur.org/docs/ Ortiz_port.pdf>. Acesso em: 20 jan. 2010.

PORTO, M. Cultura para o desenvolvimento: um desafio de todos. In: HOLLANDA, H. B.. Cultura e desenvolvimento. Rio de Janeiro: Aeroplano, 2004.

REIS, A. Economia da cultura e desenvolvimento - panorama geral e sugestão de debates para não-economistas. Rumos Itaú Cultural, Revista do Observatório, v. 2, out. 2007.

SACHS, I. Desenvolvimento e Cultura. Desenvolvimento da Cultura. Cultura do Desenvolvimento. Organizações \& Sociedade, v. 12, n. 33, p. 151-162, abr./jun. 2005.

SANTOS, M. O país distorcido: o Brasil, a globalização e a cidadania. São Paulo: Publifolha, 2002.

Por uma outra globalização: do pensamento único à consciência universal. São Paulo: Record, 2008.

TOMASSINI, L. Cultura y desarrollo. Revista de la CEPAL, no. extraordinario, out. 1998. Disponível em <http://www.eclac.cl/publicaciones/xml/4/19394/tomass.htm>. Acesso em: 21 mai. 2010.

TRENNEPOHL et al.Desenvolvimento e Cultura: relações de sinergia e conflitos. Desenvolvimento em Questão. Ijuí: Unijuí, v.5, n. 9, p. 147-161, 2007. Disponível em: 〈http://redalyc.uaemex.mx/redalyc/pdf/752/75250908.pdf>. Acesso em: 29 jun. 2010. 